\title{
AVALIAÇÃO DE MATERIAIS ORGÂNICOS EMPREGADOS COMO FERTILIZANTES
}

\author{
A.A. RODELLA; J.C. ALCARDE \\ Departamento de Qutmica-ESALQ/USP, Caixa Postal, 9 - CEP: 13418-900 - Piracicaba, SP.
}

\begin{abstract}
RESUMO: Discutiram-se os critérios de avaliação de materiais organicos empregados como fertilizantes adotados na legislação brasileira atual. Trabalhando com amostras de compostos, estercos, residuos industriais e turfa, discutiu-se a determinaçăo de carbono organico através de oxidaçăo pelo ion dicromato. Sugeriu-se que o atual método de determinação de matéria orgánica total por combustão tenha sua utilização restrita ou desaconselhada, devido aos erros grosseiros que proporciona. Como forma de se avaliar a qualidade de materiais organicos, discutiuse a deteminação da capacidade de retenção de cátions (CTC) em fertilizantes e materiais orgânicos em geral, 0 grau de maturação ou estabilidade de compostos orgánicos pâde ser convenientemente expresso através da relação entre CTC (meq/100g) e o teor de carbono orgánico expresso em porcentagem.

Describeres: fertilizante organico, carbono orgânico, capacidade de troca de cátions, turfa, compostos
\end{abstract}

\section{EVALUATION OF ORGANIC MATERIAIS USED AS FERTILIZERS}

\begin{abstract}
The present paper aimed to study the determination of organic carbon and the cation exchange capacity (CEC) of organic materials which can be used as fertilizers. Analytical procedures recommended by Brazilian official methods of fertilizer analysis include the determination of total organic matter by incineration. The errors of this method are not taken into account in spite of the great variability of the organic materials. This paper suggests that the organic characteristics of organic fertilizers must be expressed by the organic carbon content as determined by wet oxidation with dichromate ion and sulfuric acid. There is a great demand for practical indexes for determining the state of composting since the incorporation into the soil of immature organic material can cause severe damage to crops. In order to evaluate the maturity of organic products as manures, compost industrial wastes and peat, the determination of CEC was discussed. It seems possible to define the chemical stabilization of organic materials on the basis of the relationship between CEC and organic carbon content. The analytical procedures employed proved to be suitable for routine analysis.
\end{abstract}

Key Worls: organic fertilizers, organic carbon, cation exchange capacity, waste, peat, compost

\section{INTRODUÇÃO}

De maneira geral, os fertilizantes são avaliados principalmente pelo teor e pela forma química dos nutrientes presentes, através dos quais serão supridas as exigências nutricionais das plantas.

A análise química dos fertilizantes minerais permite avaliar suas especificações e verificar se estão de acordo com aquelas previstas na legislação ou garantidas pelo fornecedor. Através de técnicas tradicionais, esse controle analítico em geral é satisfatório, pois os fertilizantes são insumos constituídos basicamente por compostos químicos simples e de fórmula química definida. Fertilizantes como os fosfatos de amônio, uréia, cloreto de potássio, entre outros, apresentam características químicas como solubilidade, comportamento ácidobase e temperatura de decomposição que podem ser inferidas a partir de textos de química.
A situação é bem mais complexa com relação aos fertilizantes orgânicos e materiais orgânicos em geral, pois neles predominam compostos de alto grau de complexidade, que são os compostos orgânicos.

Compostos orgânicos podem ser vagamente caracterizados como "compostos que contém carbono". Essa classificação, contudo, é suficientemente ampla para incluir uma variedade imensa de compostos químicos que podem apresentar muito pouco em comum, além de conterem carbono em suas moléculas.

Quando se utilizam, na agricultura, fertilizantes e produtos orgânicos, pretende-se usufruir de benefícios que os adubos minerais não podem proporcionar, mas que também não são oferecidos indistintamente por qualquer material orgânico. A análise química que através de métodos simples se mostra tão adequada aos ferti- 
lizantes minerais, requer recursos mais sofisticados para avaliar fertilizantes e materiais orgânicos. A situação se mostra ainda mais complicada, quando se pretende utilizar na agricultura resi- duos orgânicos de origem industrial ou de tratamento de esgotos urbanos.

Conforme citam SAVIOZZI et al.(1988), vários parâmetros têm sido propostos para a determinação do grau de humificação de compostos: relações envolvendo teores de ácidos húmico e fúlvico, açúcares redutores, carbono total e capacidade de troca de cátions.

Matéria orgânica: $O$ parâmetro que naturalmente se destaca em importancia na avaliação de produtos orgânicos $\varepsilon$ o teor de matéria orgânica e para sua determinação a metodologia oficial brasileira (BRASIL, 1988) preconiza o método da combustão. Incinera-se uma amostra, previamente dessecada a $100-110^{\circ} \mathrm{C}$, atribuindo-se a perda de massa verificada entre 110 e $550^{\circ} \mathrm{C}$ à eliminação de matéria orgânica, principalmente como gás carbônico e água.

Tomando-se uma massa $\mathbf{M}$ de material orgânico, elimina-se a quantidade de água presente $\left(m_{1}\right)$ durante a secagem prévia. Após a incineração da massa de matéria orgânica $\left(\mathrm{m}_{2}\right)$ resta o resíduo inorgânico cuja massa $\left(m_{3}\right)$ é efetivamente determinada. Pressupõe-se assim a validade da equação:

$$
M=m_{1}+m_{2}+m_{3}
$$

e, portanto, as seguintes condições devem ser observadas:

- toda água presente deverá ser eliminada até $110^{\circ} \mathrm{C}$, seja classificada como higroscópica, capilar ou de cristalização;

- não deve haver decomposição de compostos inorgânicos;

- toda fração orgânica deve ser oxidada e eliminada.

- método parece conveniente, pois possibilita a avaliaçäo direta do teor de matéria orgânica, incluindo os diferentes tipos de compostos presentes. As condições citadas certamente podem ate prevalecer em materiais de natureza predominantemente orgânica como palhas, bagaços, estercos, tortas, e outros. E certo, con- tudo, que à medida em que se aumenta a proporção da fração mineral, é muito provável que algum de seus componentes sofra decomposição, resultando em erro positivo na determinação de matéria orgânica.

Atualmente, existe interesse no uso agronômico de uma grande variedade de resíduos industriais, ou de origem doméstica, com ênfase no aproveitamento de sua fração orgânica. Durante a incineração desses materiais, de natureza frequentemente desconhecida, será temerário desconsiderar possíveis alterações nos seus constituintes minerais.

O questionamento mais sério, entretanto, é que o método da combustão é oficialmente indicado na análise de fertilizantes organominerais. A temperatura de $550^{\circ} \mathrm{C}$ é suficientemente elevada para afetar diferentes compostos eventualmente presentes tais como: fosfatos mono e diamônico, sulfato de amônio, gesso, calcário. A perda de massa resultante da decomposição desses produtos é contabilizada juntamente com a dos compostos orgânicos e resulta em um teor de matéria orgânica superior ao real.

Para evidenciar esse efeito interferente, tomou-se uma amostra de turfa e nela determinouse $o$ teor de matéria orgânica total por combustão, obtendo-se o valor de 67,35\%. Com essa turfa, preparou-se um fertilizante organomineral onde sua proporção era de $35 \%$, após adição de sulfato de amônio, cloreto de potássio, superfosfato triplo, fosfato de monoamônio e calcário dolomítico. $O$ teor estimado de matéria orgânica na mistura organomineral seria:

$$
67,35 \times 0,35=23,57 \% \text {. }
$$

Feita a determinação de matéria orgânica pelo método da combustão, obteve-se o valor de $48,18 \%$. Observa-se que esse teor não tem nenhuma validade, pois foi afetado pela decomposição de compostos como o fosfato monoamônico $\left(190^{\circ} \mathrm{C}\right)$, sulfato de amônio $\left(235^{\circ} \mathrm{C}\right)$, carbonato de magnésio, entre outros. $\mathrm{Em}$ vista das considerações anteriores, $\epsilon$ evidente que a determinação de matéria orgânica total por combustão não pode constar de uma metodologia oficial de análise de fertilizantes sem nenhuma restrição.

Carbono orgânico: As limitações associadas à determinação de matéria orgânica por combustão sugerem que a avaliação da fração orgânica de fertilizantes e materiais orgânicos seja feita através de seu constituinte principal, ou seja, o carbono orgânico. Pode parecer desvantajoso substituir a deter- 
minação da matéria orgânica por um dos elementos que a constitui. Não se pode justificar, contudo, o emprego generalizado de um parâmetro cuja determinação pode ser a fetada por erros tão sérios.

A metodologia oficial não inclui a determinação de carbono orgânico, embora a legislação referente ao assunto (BRASIL,1983) comente a possibilidade de utilizá-la desde que seja proposta uma metodologia apropriada. Entretanto, a relação carbono-nitrogênio é considerada oficialmente como parâmetro para caracterização do grau de maturação de adubos orgânicos, sendo o carbono estimado pela expressão:

\section{$\% \mathrm{C}=(\%$ matéria orgânica total/1,8)}

O fator 1,8 pode ser seriamente questionado, pois pressupõe que a matéria orgânica dos fertilizantes orgânicos contenha invariavelmente $55,6 \%$ de carbono. Na verdade, um fator dessa ordem é utilizado para avaliação do teor de matéria orgânica do solo a partir da determinação do carbono orgânico, sendo as variações a que esta sujeito, discutidas em ALLISON, (1965).

Tomem-se como exemplo, materiais em que o constituinte orgânico predominante seja a celulose, que contendo cerca de $44,4 \% \mathrm{C}$, forneceria um fator próximo a 2,3. Um material nessas condições é a torta de filtro das usinas de açúcar, amplamente utilizada na adubação das lavouras canavieiras. Neste caso, o uso da expressão indicada, com o fator 1,8, resultaria em erro de $25 \%$ no cálculo da relação $\mathrm{C} / \mathrm{N}$.

Praticamente todo o conhecimento sobre a determinação de carbono orgânico advém dos estudos efetuados para a análise de solo. Desde as técnicas de combustão e medida de gás carbônico evoluído, os procedimentos de via úmida como os de Schollenberger e de Walkley-Black, até os processos de fracionamento e identificação de compostos como ácidos fúlvicos e húmicos, os métodos aplicados a fertilizantes ou resíduos orgânicos em geral são adaptações ou aplicações diretas de metodologias estabelecidas para a análise de solo (ALLISON, 1965).

Um dos procedimentos mais empregados é aquele baseado na oxidação do íon $\mathrm{Cr}_{2} \mathrm{O}_{7}{ }^{2}$, em presença de ácido sulfúrico. A determinaçãa do íon dicromato remanescente por titulação com íon ferroso leva ao cálculo do consumo de oxidante e, consequentemente, ao teor de carbono.

A reação de oxidação pode se processar apenas sob o calor de diluição do ácido sulfúrico ou, ainda, ser acelerada por uma fonte externa de aquecimento. Em se tratando de um composto orgânico como a glicose, a reação de oxidação se processa facilmente:

$$
\begin{aligned}
& \mathrm{C}_{6} \mathrm{H}_{12} \mathrm{O}_{6}+4 \mathrm{Cr}_{2} \mathrm{O}_{7}^{2-}+32 \mathrm{H}^{+} \longrightarrow 6 \mathrm{CO}_{2}+ \\
& 22 \mathrm{H}_{2} \mathrm{O}+8 \mathrm{Cr}^{3+}
\end{aligned}
$$

Para materiais orgânicos mais complexos, com grau de condensação elevado, a extensão da oxidação dependerá da natureza do composto, tempo de reação, intensidade do calor fornecido, presença de catalisadores.

Quando se objetiva determinar o carbono orgânico total, as condições preconizadas visam atingir a máxima eficiência na reação. Por outro lado, métodos que não se utilizam de fonte externa de calor, como o proposto por Walkley-Black, resultam em teor de carbono mais baixo que o obtido sob condições mais enérgicas, sendo então denominado "carbono prontamente oxidável".

Os conceitos discutidos anteriormente se aplicam também à análise de fertilizantes e resíduos orgânicos. Ocorre que, para produtos sujeitos à comercialização e que devem obedecer especificações e limites de tolerância, abre-se um campo fértil para a discussão quanto à validade de procedimentos analíticos. Assim, sob determinadas condições, pode-se questionar se a totalidade do carbono orgânico está ou não sendo oxidada $\mathrm{e}, \mathrm{em}$ caso negativo, podem ser sugeridos fatores visando corrigir a eficiência de oxidação ou para a conversão de carbono em matéria orgânica.

Parece mais sensato padronizar um procedimento analítico que possibilite incluir a maior parte possível do carbono orgânico presente nos materiais e, adotando-se uma postura realista, definir o teor de carbono orgânico em função do procedimento mais adequado. Essa abordagem não É estranha à metodologia de análise de fertilizantes. $\mathrm{Na}$ determinação de fósforo solúvel em solução neutra de citrato de amônio, por exemplo, o teor determinado corresponde ao que se extrai durante uma hora de agitação a $65^{\circ} \mathrm{C}$.

Capacidade de troca de cátions: Discutiu-se anteriormente, formas de se quantificar os componentes orgânicos em fertilizantes orgânicos e organominerais. Como a determinação de carbono orgânico pelo método do dicromato se fundamenta em um processo de oxidação não seletivo, nada se pode inferir sobre a natureza do material cujo teor de carbono $\epsilon$ determinado. 
Quando um material orgânico sofre transformações, originando compostos mais estáveis como o húmus, o processo pode ser acompanhado através de parâmetros mais ou menos relacionados, tais como a relação $\mathrm{C} / \mathrm{N}$, que diminui com o tempo, e as capacidades de troca de íons e de retenção de água, que aumentam.

Em vista do exposto, fica evidente que, se a determinação de carbono orgânico permite avaliar a quantidade de material orgânico presente, será também necessário avaliar seu estágio de transformação ou maturação.

A metodologia de análise de fertilizantes da Association of Official Analytical Chemists, (WILIAMS, 1984) inclui a determinação da capacidade de troca de cátions (CTC) em turfa. Consta, essencialmente, da ocupação dos sítios de troca do material com íons hidrogênio, provenientes de ácido clorídrico, lavagem do excesso de ácido, deslocamento dos íons hidrogênio com solução de acetato de bário a pH 7 e titulação do ácido acético formado. $O$ procedimento indicado por HARADA \& INOKO (1980) obedece aos mesmos princípios descritos, embora seja conduzido em escala menor com relação à massa de material e volume de soluções reagentes. Os trabalhos de LAX et al. (1986) e ROIG et al. (1988) também avaliam a CTC como parâmetro de medida do grau de humificação de estercos e materiais orgânicos em geral e preconizam o emprego de carvão ativado para prevenir perdas de material orgânico por lavagem.

O presente trabalho pretendeu discutir os parâmetros incluídos na legislação brasileira e recomendar outros que possam ser aplicados na avaliação de fertilizantes e materiais orgânicos.

\section{MATERIAL E MÉTODOS}

Foram analisados diferentes materiais orgânicos: estercos de vaca, galinha e ovelha, resíduo de tratamento de efluente da indústria de papel, torta de filtro de usina de açúcar, borra de café, serragem, composto orgânico e turfa. Esses materiais foram secos a $65^{\circ} \mathrm{C}$ e moídos para passar em peneira de $0,5 \mathrm{~mm}$ de abertura de malha.

Determinou-se o carbono orgânico nos materiais citados, pelo método tradicional de oxidação por via úmida (ALLISON, 1965), através da reação com $50 \mathrm{~mL}$ de $\mathrm{K}_{2} \mathrm{Cr}_{2} \mathrm{O}_{7} 1,25 \mathrm{~N}$ e $50 \mathrm{~mL}$ de $\mathrm{H}_{2} \mathrm{SO}_{4}$ concentrado, promovendo-seaquecimento sob refluxo durante $\mathbf{3 0}$ minutos. Foram analisadas massas variáveis de material orgânico, contendo entre 40 e $150 \mathrm{mg}$ de carbono orgânico. A conden- sação dos vapores emitidos impede que a composição da mistura se altere e, consequentemente, que a temperatura de ebulição varie durante $o$ processo de oxidação. A proporção entre solução de dicromato e ácido sulfúrico permitiu operar sob uma temperatura em torno de $150^{\circ} \mathrm{C}$, na qual são minimizados os riscos de decomposição térmica do ion dicromato. $O$ ion disromato remanescente foi quantificado por titulação com solução padronizada de sulfato ferroso amoniacal. Quantidades relativamente elevadas de dicromato de potássio e ácido sulfúrico foram empregadas, visando analisar uma amostra representativa de material orgânico.

Com o objetivo de se avaliar o efeito do tempo de aquecimento na determinação do carbono orgânico, tomando-se turfa como material orgânico de referência, efetuou-se um ensaio no qual o procedimento básico foi alterado da seguinte forma:

Tratamento A: A solução de dicromato e o ácido sulfúrico concentrado foram juntados, a mistura foi resfriada e só então adicionada ao material orgânico, permanecendo em repouso por 24 horas. Essa foi a condição menos enérgica, pois nenhum fornecimento de calor ocorreu.

Tratamento B: Não se efetuou aquecimento externo, mas a reação de oxidação do material orgânico analisado foi favorecida pelo calor de diluição do ácido concentrado na solução de dicromato.

Tratamentos $C_{10}$ a $C_{60}$ : Consistem no tratamento $B$, seguido de aquecimento sob refluxo, durante um período de 10 a 60 minutos.

O método para determinação da capacidade de troca de cátions foi, essencialmente, o descrito por WILLIAMS (1984) para turfa, com as seguintes modificações: adição de $1,0 \mathrm{~g}$ de carvão ativado à amostra, para prevenir perdas de material orgânico passível de solubilização, e substituição da solução de acetato de bário por acetato de cálcio.

\section{RESULTADOS E DISCUSSÃO}

Carbono orgánico: Os dados da TABELA 1 indicam que, mesmo sem nenhum fornecimento de calor, uma proporção relativamente elevada do carbono orgânico da turfa foi oxidada, ao considerar os valores obtidos sob aquecimento prolongado. A ação do calor de diluição favoreceu a reação, mas o aquecimento externo foi decisivo para aumentar o teor de carbono determinado. 
TABELA 1. Teores de carbono orgânico em turfa determinados sob diferentes condições de reação.

\begin{tabular}{lcc}
\hline Tratamento & \%C & \%C relativo* \\
\hline A. sem aquecimento & 36,42 & 83,9 \\
B. sob calor de diluição do $\mathrm{H}_{2} \mathrm{SO}_{4}$ & 38,07 & 87,8 \\
$\mathrm{C}_{10}$. aquecimento sob refluxo por $10 \mathrm{~min}$ & 42,00 & 96,7 \\
C $_{20}$ aquecimento sob refluxo por $20 \mathrm{~min}$ & 42,85 & 98,7 \\
C $_{30}$ aquecimento sob refluxo por $30 \mathrm{~min}$ & 43,42 & 100,0 \\
$\mathrm{C}_{40}$ aquecimento sob refluxo por $40 \mathrm{~min}$ & 43,56 & 100,3 \\
C $_{50}$ aquecimento sob refluxo por $50 \mathrm{~min}$ & 43,56 & 100,3 \\
C $_{80}$ aquecimento sob refluxo por $60 \mathrm{~min}$ & 43,30 & 99,7 \\
\hline
\end{tabular}

* teores de carbono expressos em relação ao valor obtido aos 30 min de aquecimento, considerado $=a \quad 100,0$.

Considerando-se a progressão dos resultados em função do tempo de aquecimento, $e$ que aos 30 minutos de fornecimento de calor praticamente ocorreu a estabilização da oxidação, - valor obtido nessas condições pode ser considerado como representativo do teor de carbono orgânico no material analisado.

Baseando-se nesses resultados, sugere-se que o método de oxidação pelo dicromato seja incluído na legislação para a determinação de carbono orgânico em fertilizantes orgânicos, organo-minerais e resíduos orgânicos em geral. Se em alguns desses materiais o teor de carbono orgânico assim determinado for inferior ao teor de carbono orgânico total, é viável se admitir que a fração do carbono não incluída $\epsilon$ inerte, não tendo qualquer valor agronômico.

O cálculo do teor de carbono orgânico requer o conhecimento da relação entre o número de equivalentes-grama do ín dicromato e a massa de carbono oxidada. Nesse sentido, um aspecto raramente discutido é que a citada relação varia em função da natureza do composto orgânico. Como exemplos, são apresentadas as massas de carbono que teoricamente seriam totalmente oxidadas por um equivalente-grama, ou $49,03 \mathrm{~g}$, de $\mathrm{K}_{2} \mathrm{Cr}_{2} \mathrm{O}_{7}$, determinadas através do cálculo estequiométrico: $2,00 \mathrm{~g}$ de alcool etílico; $3,00 \mathrm{~g}$ de glicose; $2,07 \mathrm{~g}$ de fenol; 3,20g de ftalato ácido de potássio; $2,76 \mathrm{~g}$ de resorcinol e 2,80g de ácido benzóico

Esse fator de variação não tem possibilidade de ser corrigido, pois exigiria conhecimentos sobre a natureza dos compostos orgânicos presentes em cada material analisado. Normalmente, toma-se como regra que um equivalente-grama do íon $\mathrm{Cr}_{2} \mathrm{O}_{7}{ }^{2-}$, ou $49,03 \mathrm{~g}$ de
$\mathrm{K}_{2} \mathrm{Cr}_{2} \mathrm{O}_{7}$, são consumidos na oxidação de $3 \mathrm{~g}$ de carbono orgânico.

Substancias inorgânicas redutoras como os íons ferroso, sulfeto, nitrito, cloreto e demais haletos também reagem com o íon dicromato. Dentre esses, o único que poderá ter um efeito interferente significativo $e ́ o$ íon cloreto, que ocorre em quantidades apreciáveis nos fertilizantes organominerais contendo cloreto de potássio.

A forma mais viável de se contornar essa interferência $\boldsymbol{\epsilon}$ aplicar a correção:

$$
\% \mathrm{C}=\% \mathrm{C} \text { determinado }-0,084 \times \% \mathrm{Cl}
$$

admitindo-se que $35,45 \mathrm{~g}$ de cloreto equivalem a $3,00 \mathrm{~g}$ de carbono na reação com o íon dicromato. A determinação de cloreto pode ser feita pelo método volumétrico de Mohr, descrita nos métodos oficiais de análise de fertilizantes (BRASIL, 1988). $\mathrm{Na}$ verdade, o efeito do íon cloreto é pouco significativo; um fertilizante organomineral que apresentasse $10 \%$ de $\mathrm{K}_{2} \mathrm{O}$, como cloreto de potássio, levaria a um acréscimo de 0,63 unidades percentuais no teor de carbono.

Capacidade de troca de cátions: Na modificação do procedimento da ASSOCIATION OF OFFICIAL ANALYTICAL CHEMISTS, empregado no presente trabalho, quantidades relativamente elevadas de 2 a 4 gramas de material foram analisadas, visando obter maior representatividade desses produtos, frequentemente heterogêneos. A quantidade total de material também determina a quantidade de ácido acético formado e, consequentemente, a precisão dos resultados na titulação final. 
Verificou-se que o carvão ativado retém eficientemente os compostos orgânicos passíveis de solubilização nas exaustivas lavagens efetuadas. 0 carvão ativado utilizado não apresentou retenção de cátions significativa $\mathrm{e}$, caso manifestasse algum efeito, o mesmo seria computado através da "prova em branco".

O acetato de cálcio foi empregado em substituição ao acetato de bário por ser mais acessível, embora este último tenha menor efeito na solubilização de compostos orgânicos que o sal de cálcio. Entretanto, desde que se empregou o carvão ativado, esta preocupação deixa de ser relevante.

A importância do parâmetro CTC, na avaliação de materiais orgânicos, pode ser evidenciada pelos resultados obtidos para uma série de misturas de adubo mineral com serragem e turfa, mostrados na TABELA 2.

Observa-se que 0 teor de carbono orgânico não permite diferenciar as misturas, pois todas apresentam valores similares, próximos a 16\%. A capacidade de retenção de cátions, contudo, demonstra claramente as diferenças de qualidade do material orgânico, provocada pela substituição de turfa por serragem.

$\mathrm{Na}$ comparação entre diferentes materiais orgânicos, pode-se sugerir como parâmetro o número de miliequivalentes de carga por grama de carbono orgânico presente $(\mathrm{meq} / \mathrm{g})$, ou seja a relação CTC/\%C.

Os dados mostrados na TABELA 3 incluem dentre os diversos materiais analisados, alguns onde o elevado teor de carbono orgânico está relacionado a baixos valores de CTC, refletindo um material com baixo grau de humificação. É o caso da borra de café e da torta de filtro. $O$ resíduo proveniente do tratamento de efluentes da indústria de papel revelou uma qualidade surpreendente em termos de retenção de cátions, provavelmente por conter material orgânico finamente subdividido. De maneira geral, a relação $\mathrm{CTC} / \% \mathrm{C}$ permitiu a caracterização dos diferentes materiais orgânicos estudados ressaltando suas peculiaridades.

A relação $\mathrm{CTC} / \% \mathrm{C}$ foi considerada por ROIG et al. (1988) como mais apropriada que a relação $\mathrm{C} / \mathrm{N}$, para indicar o grau de humificação de materiais orgânicos, pois esta pode ser afetada seriamente pela presença de nitrogênio amoniacal, como ocorre no esterco de galinha.

$\mathrm{Na}$ verdade, os diferentes parâmetros citados na literatura estão correlacionados em maior ou menor grau, pois refletem basicamente o mesmo processo de reações de estabilização de compostos orgânicos. A vantagem da utilização da capacidade de troca de cátions é que, além de qualificar o material orgânico, esse índice traz uma informação muito significativa do ponto de vista agronômico, ou seja, a melhoria de retenção de nutrientes que esses produtos podem proporcionar ao serem incorporados ao solo.

\section{CONCLUSÕES}

O método de determinação de carbono orgânico por via úmida, através da oxidação pelo ín dicromato, deve ser adotado na avaliação de materiais orgânicos empregados como fertilizantes.

Um tempo de ebulição de 30 minutos pode ser sugerido como suficiente para incluir na determinação a maior parte, senão a totalidade, do carbono orgânico presente na amostra, dispensando-se o uso de fatores para avaliação de um "teor de carbono orgânico total".

TABELA 2. Teores de carbono orgânico e capacidade de troca de cátions (CTC) em misturas organominerais contendo $41 \%$ de material orgânico e $59 \%$ da mistura fertilizante 5-25-25.

\begin{tabular}{|c|c|c|c|c|c|}
\hline Mistura & serragem & ${ }^{\text {turfa }}$ & $\begin{array}{c}\text { CTC } \\
\text { meq } / 100 \mathrm{~g}\end{array}$ & $\% \mathrm{C}$ & $\begin{array}{l}\text { relação } \\
\text { CTC/\%C }\end{array}$ \\
\hline A & 41 & 0 & 5,48 & 15,55 & 0,35 \\
\hline B & 33 & 8 & 15,12 & 16,61 & 0,91 \\
\hline C & 25 & 16 & 23,85 & 16,61 & 1,44 \\
\hline D & 16 & 25 & 33,26 & 16,57 & 2,01 \\
\hline E & 8 & 33 & 41,66 & 16,00 & 2,60 \\
\hline F & 0 & 41 & 51,57 & 15,25 & 3,38 \\
\hline
\end{tabular}


TABELA 3. Teor de carbono orgánico (\%C) e capacidade de troca de cátions (CTC), em diferentes materiais, apresentados juntamente com os desvios padrōes relativos (dp\%), como médias de três repetições.

\begin{tabular}{llllll}
\hline material & $\begin{array}{c}\text { carbono } \\
(\%)\end{array}$ & $\begin{array}{c}\text { d.p. } \\
\text { \% }\end{array}$ & $\begin{array}{c}\text { CTC } \\
\text { eq/100g }\end{array}$ & $\begin{array}{c}\text { d.p. } \\
\%\end{array}$ & CTC/C \\
\hline composto A & 14,0 & 5,2 & 30,4 & 5,5 & 2,2 \\
composto B & 21,1 & 3,0 & 31,5 & 0,9 & 1,5 \\
borra de cafe & 54,7 & 0,6 & 42,5 & 0,9 & 1,0 \\
esterco de ovelha & 38,9 & 0,7 & 40,8 & 2,1 & 1,0 \\
esterco de vaca & 38,4 & 1,0 & 44,4 & 0,7 & 1,2 \\
esterco de galinha & 16,9 & 4,3 & 40,3 & 1,0 & 2,4 \\
torta de filtro & 42,2 & 0,9 & 40,4 & 0,6 & 1,0 \\
res. ind. de papel & 16,0 & 1,9 & 78,6 & 4,2 & 4,9 \\
turfa & 43,3 & 0,8 & 123,3 & 0,2 & 2,8 \\
\hline
\end{tabular}

A relação entre a capacidade de troca de cátions e o teor de carbono orgánico pode ser empregada satisfatoriamente para avaliar a qualidade do carbono orgânico, ou seja, o grau de maturação dos materiais orgânicos empregados na agricultura.

\section{REFERENCIAS BIBLIOGRÁFICAS}

ALLISON, L.E. Organic carbon. In: BLACK, C.A. (Ed.) Methods of soil analysis. Madison: American Society of Agronomy, 1965. Pt.2; Chemical and Microbiological Properties, p.1367-1378

BRASIL. Ministério da Agricultura. Secretaria Nacional de Defesa Agropecuária. Analise de corretivos, fertilizantes e inoculantes; métodos oficiais. Brasilia, 1988. 104p.

BRASIL. Leis, Decretos, etc. Portaria $n^{\circ} 01$, de 04 de março de 1983. Dif́rio Oficial, Brasilia, 09 de Março de 1983. Dispōe sobre a inspeção e fiscalização da produção e do comércio de fertilizantes, corretivos, inoculantes, estimulantes ou biofertilizantes destinados agricultura.
HARADA, Y.; INOKO, A. The measurement of the cation exchange capacity for estimations of degree of maturity. Soil Science and Plant Nutrition, Tokyo, v.26, n.1, p.127-134, 1980.

LAX, A.; ROIG, A.; COSTA, F. A method for determining the cation exchange capacity of organic materials. Plont and Soil, The Hague, v.94, p.349-355, 1986.

ROIG, A.; LAX, A.; CEGARRA, J.; COSTA, F. Cation exchange capacity as a parameter for measuring the humification degree of manure. Soil Science, Baltimore, v.146, n.5, p.311-316, 1988.

SAVIOSI, A.; LEVI-MINZI, R. RIFFALDI, $R$. Maturity evaluation of organic waste. Biocycle, Emmaus, v.29, n.3, p.54-56, 1988.

WILLIAMS, S. (Ed.) Oficial methods of anglysis of the ascociation of officinl analytical chemists. 14.Ed. Arlington: AOAC, 1984. 1141p.

Recebido para publicação em 04.01.94

Aceito para publicação em 10.03.94 